\title{
Análise comparativa de elementos físico-químicos e contaminantes em corpo d'água do Riacho Grilo no estado de Sergipe
}

Comparative analysis of physical-chemical and contaminant elements in the body of the water of Riacho Grilo in the state of Sergipe

Análisis comparativo de elementos fisicoquímicos y contaminantes en el cuerpo de agua del Riacho Grilo en el estado de Sergipe

\begin{abstract}
RESUMO
Este estudo objetivou analisar e comparar parâmetros físico-químicos e bacteriológicos do Riacho Grilo, localizado em Sergipe, com os resultados da análise de 2009 pela SEMARH. A metodologia utilizou-se dos dados coletados em maio de 2015, para desenvolver um estudo comparativo com tal análise de 2009, acrescida do cobre total na água. A coleta das amostras foi in loco, com presença de mata ciliar e ausência de lixos na área. Notou-se sutil diferença entre os modelos devido à forte chuva nos dias da coleta. No entanto, o fósforo, cloreto e coliformes apresentaram alterações significativas, sendo que, os dois primeiros indicam contaminação por produtos químicos, e os coliformes reduzidos podem ser derivados da chuva e dos valores para sólidos totais que podem levar a um acúmulo de bactérias. Como resultado, o nível de cobre encontrado torna o uso da água imprópria. DESCRITORES: Água; Riacho; Análise Físico-Química; Coliformes.
\end{abstract}

\section{ABSTRACT}

This study aimed to analyze and compare the physical-chemical and bacteriological parameters of Grilo Stream, located in Sergipe, with the analysis performed in 2009 by SEMARH. The methodology used the data collected in May 2015, to develop a comparative study with this analysis of 2009 , plus the total copper in the water. The collection of samples was in loco, with the presence of riparian vegetation and absence of waste in the area. A subtle difference was noted between the models due to heavy rain on collection days. However, phosphorus, chloride and coliforms showed significant changes, with the first two indicating contamination chemicals, and reduced coliforms can be derived from the rain and values for total solids, which can lead to an accumulation of bacteria. As a result, the level of copper found makes the use of water inappropriate.

ESCRIPTORS: Water; Stream; Physicochemical analysis; Coliforms.

\section{RESUMEN}

Este estúdio tuvo como objetivo analizar y comparar parâmetros físico-químicos y bacteriológicos de Riacho Grilo, ubicado em Sergipe, com los resultados del analisis de 2009 de la SEMARH. La metodologia utilizó los datos recolectados em mayo de 2015 , para desarrollar un estudio comparativo con esta analisis de 2009, más el cobre total en el agua. La recolección fue in loco, com presencia de bosque de ribera y ausencia de desechos em la zona. Se notó una sutil diferencia entre modelos debido a fuertes lluvias en los días de recolección. Sin embargo, fósforo, cloruro y coliformes disipados, los dos primeros indican contaminación por químicos y coliformes reducidos que pueden separarse de la lluvia y los valores para sólios totales que pueden conducir a la acumulación de bactérias. Como resultado, el nível de cobre encontrado hace que su médico utilice el agua.

DESCRIPTORES: Agua; Arroyo; Análisis Físico-Químico; Coliformes.

RECEBIDO EM: 27/10/2020 APROVADO EM: 30/10/2020

\section{Raphaella Ingrid Santana Oliveira}

Professora no Centro Universitário Estácio de Sergipe, Graduada em Biomedicina, Mestre em Biotecnologia Industrial, Universidade Tiradentes, Aracaju, Brasil.

ORCID: 0000-0002-7027-9049 


\section{Sheila Santos Araújo}

Graduada em Biomedicina, Universidade Tiradentes, Aracaju, Brasil.

ORCID: 0000-0002-1396-703X

\section{Cinthia Larissa Santana Lisboa}

Graduada em Biomedicina, Universidade Tiradentes, Aracaju, Brasil.

ORCID: 0000-0002-3680-5789

\section{Angelina Freire Resende}

Graduada em Biomedicina, Universidade Tiradentes, Aracaju, Brasil.

ORCID: 0000-0002-7437-5273

\section{Thaize Souza Santos}

Graduada em Biomedicina, Universidade Tiradentes, Aracaju, Brasil.

ORCID: 0000-0003-1610-1773

\section{Lumar Lucena Alves}

Medical Technologist, Gerald Champion Regional Medical Center - GCRMC, NM, USA, Graduado em Biomedicina, Universidade

Tiradentes, Aracaju, Brasil.

ORCID: 0000-0002-0375-1286

\section{Luan Lucena Alves}

Graduando em Ciências Biológicas, Universidade Paulista, São Paulo, Brasil.

ORCID: 0000-0003-2414-6840

\section{Weslen Lima Silva}

Graduando em Biomedicina, Centro Universitário Estácio de Sergipe, Aracaju, Brasil.

ORCID: 0000-0003-0397-5818

\section{INTRODUÇÃO}

0 Estado de Sergipe é banhado por 8 bacias hidrográficas ${ }^{1}$ são elas: São Francisco, Japaratuba, Sergipe, Vaza Barris, Piauí e Real Costeira ${ }^{1}$ que abrange os povoados Caueira e Abaís; e Costeira ${ }^{2}$ que contempla Sapucaia ${ }^{2}$. Entre elas está a do Rio Piauí, considerada estadual uma vez que a sua nascente se encontra em maior parte dentro do Estado $^{3}$. A bacia hidrográfica do rio Piauí está situada na parte sul do estado de Sergipe. Possui uma área de drenagem de 4.150 $\mathrm{km}^{2}$, abrangendo 15 municípios, sendo totalmente inseridos seis municípios: Salgado, Santa Luzia do Itanhy, Estância, Boquim, Pedrinhas e Arauá4 com extensão de $166.93 \mathrm{~km}$, ou seja, equivalente a quase $19 \%$ de seu comprimento e atende as necessidades de 15 municípios. Além disso, possui nascente no estado da Bahia, na Serra dos Palmares, nos municípios sergipanos de Riachão do Dantas e Simão Dias ${ }^{3}$.
O Rio Piauí corta o estado de Sergipe no sentido oeste-leste, tendo como principais afluentes: Piauitinga, Fundo, Quebradas, Guararema e Arauá, sendo dividido em duas regiões climáticas: região sub úmida e região do agreste 5 . Entre os afluentes, destaca-se o Rio Piauitinga, que corresponde a margem esquerda do Rio Piauí, onde encontra-se o Riacho Grilo, situado na região sub úmida, em que estão inseridos os municípios de leste do Riachão do Dantas, sul de Boquim, norte de Pedrinhas, Salgado, leste de Arauá, Santa Luzia do Itanhy, Umbaúba e Itabaianinha6. A bacia hidrográfica localiza-se entre as coordenadas geográficas (SAD 69) $10^{\circ} 34^{\prime} 10^{\prime \prime}$ e $10^{\circ} 45^{\prime} 12^{\prime \prime} S$ (latitude)

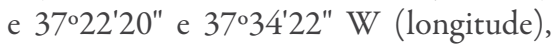
com área total de $418,20 \mathrm{~km}^{2}$, e drena partes do território dos Municípios de Lagarto, Boquim, Itaporanga D'Ajuda, Salgado e Estância ${ }^{7}$.

O Riacho Grilo está localizado na região centro-sul do estado de Sergipe, abastecendo a sua sede, o município de Salga- do, com população de 19.365 habitantes pelo último senso de 2010, com estimativa atual de 20.025 habitantes com uma área de $247.579 \mathrm{~km}^{2}$ e distância de até $54 \mathrm{Km}$ da capital. Abastece também o município de Boquim com $^{8}$ população de 25.533 habitantes pelo senso de 2010 e estimativa atual de 26.899 habitantes, com área de $205.643 \mathrm{Km}^{2}$ e distância de $82 \mathrm{Km}$ da capital'.

Segundo Santos10, o Riacho Grilo "tem grande importância nessa região por ser responsável pelo abastecimento de água de 16.329 habitantes da sede e 3 povoados do município de Boquim”. Após sua água ser tratada pela rede de distribuição das regiões, é utilizada para higiene pessoal, uso doméstico, no consumo pela agropecuária, na irrigação em plantações, na sustentabilidade da vegetação nativa e na indústria ${ }^{10}$. Em geral todos os rios possuem características culturais da sociedade em que estão inseridos.

A poluição química de natureza orgânica ou inorgânica é o que causa um 
dos problemas mais sérios que afetam o meio ambiente ${ }^{11}$, decorrente da introdução de fertilizantes, pesticidas, produtos químicos em geral, presença da água drenada na área agrícola, derramamentos de esgoto sanitário ou até mesmo a presença de indústrias que utilizam metais pesados podendo poluir águas e persistir em corpos hídricos ${ }^{12}$. Problemas como estes podem atingir a população que utilizam do abastecimento da água como fonte de alimento e lazer, podendo trazer problemas de saúde associados à sua ingestão. A utilização de fertilizantes e agrotóxicos nas lavouras podem promover a contaminação do solo, pois alguns fertilizantes contêm em sua composição metais pesados, tal característica pode contribuir na maximização do conteúdo tóxico do solo ${ }^{13}$. Os metais pesados, a partir da água proveniente da pluviosidade, podem ser transportados pela força da gravidade infiltrando nos espaços vazios do solo, contaminando os diversos reservatórios de água, bem como as diferentes formas de vida que habitam este ambiente ${ }^{14}$.

Diante disso, torna-se pertinente averiguar a situação da água do Riacho Grilo do estado de Sergipe, uma vez que se questiona sobre o seu consumo ser apto à população de acordo com a resolução vigente. Desta forma, o presente artigo teve como objetivo analisar os parâmetros físico-químicos e bacteriológicos do Riacho Grilo, comparar os resultados com a análise feita no ano de 2009 pela Secretaria de Estado do Meio Ambiente e dos Recursos Hídricos (SEMARH) para a configuração do Programa Nacional de Desenvolvimento dos Recursos Hídricos PROÁGUA Nacional que foi realizada com base na portaria $n^{\circ} 357 / 2005$ para Classe 2 de águas da Resolução do Conselho Nacional de Meio Ambiente - CONAMA.

\section{MÉTODOS}

Constou de pesquisa documental na Secretaria dos Recursos Hídricos do Estado de Sergipe localizada no município de Aracaju, que possibilitou a obtenção de dados construídos por aquela instituição referente ao ano de 2009.

Além de um estudo bibliográfico, um estudo in loco simples foi realizado a fim de avaliar amostras de água do Riacho Grilo no povoado Grilo, município de Salgado/ SE. A coleta foi realizada no dia 22 de maio de 2015 no período da manhã às 9:58 am e foram utilizados recipientes plásticos estéreis de boca larga para a coleta de 1000 $\mathrm{mL}$ de água para avaliação. É importante destacar que a situação climática se encontrava em estado chuvoso. Durante a mesma, foram utilizadas duas luvas para proteção contra agentes bacteriológicos e esta foi feita contra a correnteza na superfície do corpo hídrico. Todas as recomendações exigidas pelo laboratório foram obedecidas. As análises foram realizadas no Laboratório de Estudos Ambientais (LEA) do Instituto de Tecnologia e Pesquisa (ITP). Os padrões foram fracionados e identificados conforme o regulamento utilizado pelo ITP. Para a determinação do número mais provável $(\mathrm{NMP} / \mathrm{g})$ de coliformes totais e termotolerantes, as análises foram realizadas no laboratório de Estudos Ambientais do ITP. Todas as análises foram realizadas no dia 22 de maio de 2015.

$\mathrm{Na}$ análise microbiológica dos Coliformes Totais e Termotolerantes, foram utilizadas alíquotas de $25 \pm 0,2 \mathrm{~mL}$ em solução salina peptonada a $0,1 \%$ até a obtenção de solução 10-1 e a 10-3. Além disso, o teste presuntivo foi realizado em série de 5 tubos contendo caldo lauril sulfato triptose, incubados a $35-37^{\circ} \mathrm{C}$ por $24-48 \mathrm{~h}^{15}$.

Foram considerados positivos os tubos que ocorreram turvação e formação de gás nos tubos de Duran. Em seguida, foram realizados testes confirmatórios para Coliformes Totais e Termotolerantes onde, para Coliformes Totais, o caldo presente nos tubos positivos foi semeado em tubos contendo Caldo Verde Bile Brilhante (VBBL) e incubados em estufa a $35-37^{\circ} \mathrm{C}$ por 48 horas e, para Coliformes Termotolerantes, semeado em Caldo E. coli (EC), incubados a $45,5^{\circ} \mathrm{C}$ por 24 horas. Os valores de NMP/g foram calculados de acordo com Silva et al. ${ }^{16}$.

Os demais parâmetros analisados fo- ram os que constavam nos dados referentes ao ano de 2009: temperatura da amostra (campo), turbidez, $\mathrm{pH}$ (campo), cloretos, sólidos totais, sólidos totais dissolvidos, amônia, nitrogênio-nitrito e fósforo total. O único acrescido foi o cobre total. Para a análise dos parâmetros inorgânicos, os elementos foram quantificados por meio da técnica de Espectrometria de Emissão Óptica com Fonte de Plasma indutivamente acoplado - ICP-OES (Optima 8000 PerkinElmer) através do Método de Determinação 3111B da American Water Works Association ${ }^{17}$. Esta técnica permite a quantificação dos elementos químicos presentes na amostra baseada na propriedade dos átomos ou íons excitados emitirem radiação eletromagnética nas regiões do espectro eletromagnético visível. O plasma atua possibilitando a quantificação de uma extensa faixa de analitos, uma vez que possui energia suficiente para gerar a excitação dos elementos químicos. Além disso as amostras passaram por um procedimento de digestão ácida com o objetivo de remover os compostos orgânicos presentes, facilitando assim a leitura dos compostos inorgânicos desejados ${ }^{17}$. A avaliação da turbidez, amônia, nitrogênio-nitrito e fósforo foi realizada através do Espectofotômetro DR 6000 UV-VIS (Hach) através de identificação por radiofrequência (RFID). Adicionalmente, a avaliação para sólidos totais e sólidos totais dissolvidos foi realizada por meio de condutivímetro (DM-32 Digimed). Os resultados obtidos foram tabulados utilizando o software Microsoft Excel para posterior comparação e discussão com os dados publicados anteriormente pela DESO (Departamento de Saneamento de Sergipe) em 2009.

Além da coleta dos dados e análise dos parâmetros, foi realizada uma visita à região com o intuito de observar os impactos ambientais, fenômenos naturais, sem presença de lixos em lugares indevidos (na área de análise) e presença da mata ciliar.

\section{RESULTADOS}

Os resultados das análises bacterioló- 


\section{artigo}

Oliveira, R.I.S.; Araújo, S.S.; Lisboa, C.L.S.; Resende, A.F.; Santos, T.S.; Alves, L.L.; Alves, L.L.; Lima Silva, W.;

Análise comparativa de elementos físico-químicos e contaminantes em corpo d'água do Riacho Grilo no estado de Sergipe

gicas e físico-químicas do ano de 2015, seguem abaixo na tabela 1 :

Os dados coletados através de pesquisa documental referente ao Riacho Grilo seguem abaixo na tabela 2. Estes permitem a comparação, análise e apresentação de possíveis explicações e/ou soluções.

Dentre as informações coletadas foram observadas uma irrisória diferença entre os parâmetros das tabelas de 2015 e 2009 devido à forte chuva nos dias anteriores e durante a coleta da amostra, além da margem de erro da análise, são eles: temperatura, $\mathrm{pH}$, amônia, nitrogênio/nitrato e turbidez. O fósforo encontra-se nulo na segunda tabela, enquanto na primeira possui concentração de $0,262 \mathrm{mg} / \mathrm{L}$. Além disso, houve um aumento do Cloreto na tabela

Tabela 1. Análises bacteriológicas e físico-químicas do Riacho Grilo no ano de 2015.

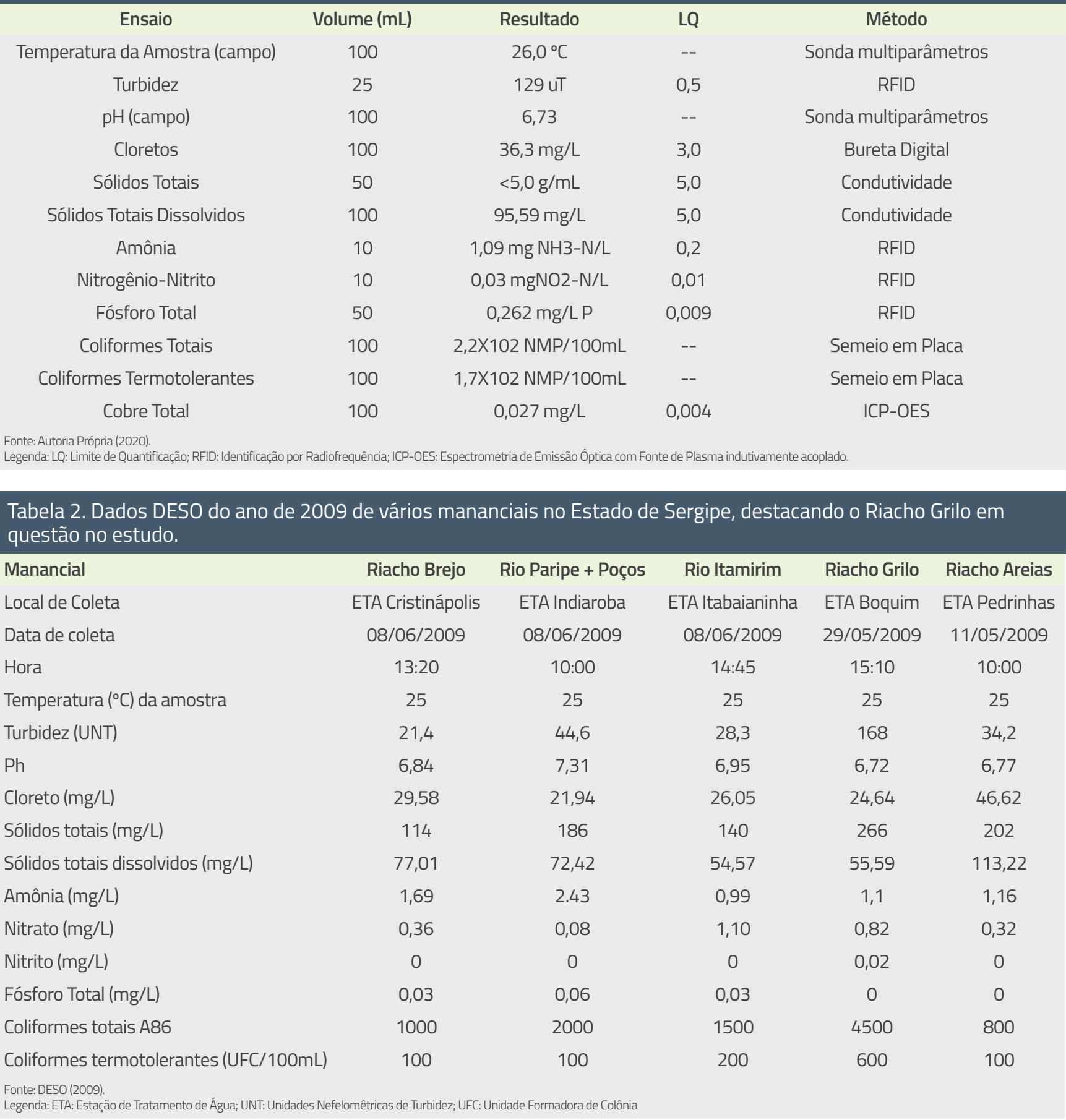


de 2015 em relação a de 2009. Ocorreu também uma elevação dos sólidos em geral na primeira tabela, em relação a segunda, com uma redução dos Coliformes na tabela de 2015. É importante ressaltar que os parâmetros sólidos totais na primeira tabela se encontram na unidade $\mathrm{g} / \mathrm{mL}$ e na segunda em $\mathrm{mg} / \mathrm{L}$.

$\mathrm{Na}$ análise realizada, em virtude da alta utilização científica em indústrias do metal cobre, foi acrescentado o teste para este metal pesado, que em baixas doses é essencial para o ecossistema. Assim, o valor de cobre dissolvido na amostra de 2015 se apresentou com $0,027 \mathrm{mg} / \mathrm{L}$, considerada uma concentração elevada. Outrossim, na visita à região, com o intuito de observar os impactos ambientais e fenômenos naturais do local, não foi constatada a presença de lixos em lugares indevidos na área de análise e esta apresentou uma grande presença da mata ciliar.

\section{DISCUSSÃO}

Diante das análises realizadas, a obtenção do fósforo nulo na segunda tabela, enquanto nos resultados das análises possui concentração de $0,262 \mathrm{mg} / \mathrm{L}$, se dá em virtude da presença de fertilizantes, pesticidas, produtos químicos em geral ou pela presença da água drenada na área agríco$1 \mathrm{a}^{12}$ que pode provocar excesso de fósforo nos recursos hídricos. Para estar nulo, ou houve diminuição destes fatores ou foi resultante das chuvas que causaram diluição, mascarando este dado.

O aumento do Cloreto pode ter ocorrido devido à intrusão da cunha salina, e também, por algum derramamento de esgoto sanitário em seu afluente (Rio Piauitinga) podendo ter seguido o percurso para seu subafluente (Riacho Grilo). Embora o teste de coliformes fecais seja mais específico, a avaliação do cloreto serve como indicador de contaminação por esgoto sanitário, podendo associar a sua elevação em um rio com derramamento de esgotos. Além disso, ele tem um fator importante sobre os ecossistemas aquáticos uma vez que microrganismos sofrem influência na alteração da sua pressão osmótica celular ${ }^{18}$. Ademais, foi possível notar uma elevação dos sólidos em geral na primeira tabela. Esta elevação de sólidos totais possibilita a uma retenção de bactérias no fundo dos rios e, como consequência, pode justificar a redução dos Coliformes nos resultados obtidos.

\section{O cobre em baixas}

doses é essencial

para o ecossistema,

portanto é

importante se

obter até o valor

máximo de cobre

dissolvido para

Classe 2

de águas em

$0,009 \mathrm{mg} / \mathrm{L}$

O cobre em baixas doses é essencial para o ecossistema, portanto é importante se obter até o valor máximo de cobre dissolvido para Classe 2 de águas em 0,009 mg/L (CONAMA no 357/2005) ${ }^{19}$. Assim, o valor permitido discorda com o valor encontrado no resultado da amostra de 2015. Se encontrado em uma concentração elevada, a ingestão continuada deste metal acima dos níveis dietéticos dos animais pode levar a um acúmulo do elemento em vários tecidos, principalmente no fígado, levando à uma eventual intoxicação ${ }^{18}$. Em adição, o acúmulo de metais pesados em organismos aquáticos compromete toda a cadeia trófica já que o metal é acumulado por um processo conhecido como bioacumulação. Desta maneira, os organismos topo de cadeia tendem a apresentar maiores concentraçóes do metal do que aqueles de base de cadeia ${ }^{20}$. Sinais clínicos podem ser observados como náuseas, apatia, vômito, diarreia hemorrágica, problemas renais e hepáticos ${ }^{21}$. Portanto, segundo a resolução do CONAMA vigente os resultados tornam a água imprópria para o uso característico de sua classe.

Os resultados desse trabalho estão de acordo com a portaria da Resolução do Conselho Nacional de Meio Ambiente CONAMA n ${ }^{\circ} 357 / 2005$ para Classe 2 de águas, com poucas alterações entre os parâmetros ${ }^{19}$. Sabendo que a presença de certas substâncias na composição das águas se faz necessária para a manutenção da vida de organismos aquáticos, o comparecimento de substâncias estranhas à sua composição devido as ações inadequadas do homem ao meio ambiente, têm prejudicado o seu uso e seu equilíbrio dinâmico ${ }^{22}$. Assim, esse resultado confirmou a importância de atender a essa portaria, considerando que o bem-estar e a saúde do ser humano, bem como a proteção das comunidades aquáticas e o equilíbrio ecológico aquático são dependentes da qualidade das águas. Além do mais, o fato de não ser constatada a presença de lixos em lugares indevidos na área de análise, possibilita entender que a região é pelo menos preservada contra a ação humana. Entretanto, é preciso conceder mais atenção à presença de certas substâncias, alertando aos cidadãos sobre a necessidade de adoção de atitudes e medidas que possam garantir as características químicas e microbiológicas, com o intuito de desenvolver condições sanitárias adequadas da água de consumo ${ }^{23}$.

\section{CONCLUSÃO}

Além de outras utilizações, as águas do Riacho Grilo abastecem dois municípios de Sergipe, Salgado e Boquim. O mesmo segue bem conservado em todos os seus aspectos: mata ciliar conservada, fluxo contínuo e pouco contato com os animais daquela região. Portanto, conclui-se que 


\section{artigo}

Oliveira, R.I.S.; Araújo, S.S.; Lisboa, C.L.S.; Resende, A.F.; Santos, T.S.; Alves, L.L.; Alves, L.L.; Lima Silva, W.

Análise comparativa de elementos físico-químicos e contaminantes em corpo d’água do Riacho Grilo no estado de Sergipe

a sua drenagem para o abastecimento durante o período analisado de 2009 a 2015 não aponta que tenha causado impactos ambientais para o Riacho.

Dentre os resultados das análises bacteriológicas e físico-químicas, os dados referentes a fósforo e cloreto são indicativos de introdução de produtos químicos no Riacho Grilo. A diminuição da presença de coliformes pode ser decorrente da chuva e dos valores para sólidos totais que podem levar a uma retenção de bactérias. Segundo a resolução do CONAMA vigente, o valor elevado de cobre na amostra torna o Riacho Grilo impróprio para o uso da água em sua classe, necessitando de novas análises para maior averiguação.

A finalidade dos estudos permitiu apresentar um debate a respeito da situação atual da via subafluente, além de criar uma reflexão sobre a sustentabilidade que garantiriam um controle do ambiente em pesquisa. É necessário ressaltar a quantidade insuficiente de artigos recentes acerca da área territorial e hidrográfica do estado de Sergipe. Espera-se que o presente trabalho sirva de discussão para futuros estudos.

\section{REFERÊNCIAS}

1. CONERH, Resolução Nº 27 DE 04 de novembro de 2015. Conselho Estadual de Recursos Hídricos. Diário Oficial da União 28 abril 2016.

2. Barbosa AMF, Oliveira AF, Silva LCS, Melo R, Santos SSC. Bacias Hidrográficas e os Conflitos pelos usos das Águas no Estado de Sergipe. Rev Franco-Brasileira de Geografia 2019; 40(40):1-19.

3. Araújo AT. Geografia de Sergipe. Aracaju; 1969.

4. Ishizawa YB; Barbosa AG; Mendes LA. Análise da influência dos fenômenos El Niño e La Niña na oscilação da precipitação na bacia do rio Piauí, Sergipe. [Apresentação no $6^{\circ}$ Congresso Internacional De Tecnologias Para 0 Meio Ambiente; 2018; Bento Gonçalves-RS, Brazil].

5. Silva TS; Brito PLC; Santos GS; Magalhães ID; Souza RB; Almeida CAC. Diagnóstico ambiental de nascentes na bacia hidrográfica do Rio Piauí, Alagoas. Revista Verde de Agroecologia e Desenvolvimento Sustentável 2018; 13(3):399-03.

6. Campos JL. Geografia de Sergipe. Aracaju; 1967.

7. Oliveira DG; Ferreira RA; Mello AA; Oliveira RSC; Oliveira RSC. Análise da Vegetação em nascentes da bacia hidrográfica do Rio Piauitinga, Salgado, SE. Revista Árvore 2012; 36(1):127-41.

8. Instituto Brasileiro de Geografia e Estatística [ftp://ftp.ibge. gov.br/Estimativas_de_Populacao/Estimativas_2013/estimativa_2013_dou.pdf]. Estimativas da População Residente nos Municípios Brasileiros com Data de Referência em $1^{\circ}$ de julho de 2013 [Acesso em 04 abr. 2020]. Disponível em: http:www. ibge.com.br

9. Instituto Brasileiro de Geografia e Estatística [http://www. ibge.gov.br/home/estatistica/populacao/censo2010/tabelas_ pdf/total_populacao_sergipe.pdf]. Censo Demográfico 2010 [Acesso em: 23 set. 2020]. Disponível em: http:www.ibge.com.br

10. Santos TIS. Estado de conservação e aspectos da vegetação de nascentes do Riacho Grilo-SE. Aracaju. Dissertação [Mestrado em Agroecossistemas] - Universidade Federal de Sergipe; 2009.

11. Aguiar MRMP; Novaes AC; Guarino AWS. Remoção de metais pesados de efluentes industriais por aluminossilicatos. Quím. Nova 2015; 25(6b):1145-54.

12. Raupp DT; Fransciscato L; Lima LB. Abordando a Temática poluição hídrica no Ensino Médio: uma proposta de sequência didática com foco nos contaminantes emergentes para o ensino de funções orgânicas mistas. Revista Brasileira de Ciência e
Movimento 2019; 2(2):407-30.

13. Silva ES; Jesus RS. Caracterização Geoambientais do Rio Machado na área do bairro Matinha em Lagarto/SE. Sergipe. Monografia [Especialização em Território, Desenvolvimento e Meio Ambiente] - Universidade Federal de Sergipe; 2012.

14. Santos LS; Freitas VM. Poluição do solo e da água. [Apresentação no IV Colóquio Estadual de Pesquisa Multidisciplinar e Il Congresso Nacional de Pesquisa Multidisciplinar; 2019; Minas Geais, Brasil].

15. Vanderzant C; Splittstoesser DF. Compendium for the microbiological examination of foods. 3th ed. Washington, DC: American Public Health Associon; 1992.

16. Silva N; Junqueira VCA; Silveira NFA. Manual de métodos de análise microbiológica de alimentos. 2nd ed. São Paulo: Livraria Varela; 2001.

17. Centro Analítico De Instrumentação Da Universidade De São Paulo. Espectrometria de emissão óptica com plasma - ICP OES. São Paulo, 2015.

18. Estado De São Paulo. Secretaria do Meio Ambiente [http:// www.ambiente.sp.gov.br/aguas-interiores/files/2013/11/variaveis.pdf]. Significado ambiental e sanitário das variáveis de qualidade das águas e dos sedimentos e metodologias analíticas e de amostragem [acesso em 06 abr. 2020]. Disponível em: http:www.cetesb.sp.gov.br

19. Brasil. Resolução N³57, de 17 de março de 2005. Publicada no Diário oficial da União 18 mar 2005; 053.

20. Lima DP; Santos C; Silva RS; Yoshioka ETO; Bezerra RM; Contaminação por metais pesados em peixes e água da bacia do rio Cassiporé, Estado do Amapá, Brasil. Acta Amazonica 2015; 45(4), 405-14.

21. Guerra TA. Cobre: Deficiência e Intoxicação [Seminário apresentado na disciplina Transtornos metabólicos dos animais domésticos, no Programa de Pós-Graduação em Ciências Veterinárias da UFRGS; 2008; Rio Grande do Sul, Brasil].

22. Soares EM; Ferreira RL. Avaliação da qualidade da água e a importância do saneamento básico no Brasil. Revista Meio Ambiente e Sustentabilidade 2017; 13(6):50-76.

23. Mello FA; Olivo AM. Recursos Hídricos: Poluição, escassez, qualidade microbiológica e química da água. Coloquium Vitae, 2016; 8(especial):36-42. 